\title{
RADIOACTIVE IODINE AS AN INDICATOR IN THYROID PHYSIOLOGY. V. THE USE OF RADIOACTIVE IODINE IN THE DIFFERENTIAL DIAGNOSIS OF TWO TYPES OF GRAVES' DISEASE ${ }^{1,2}$
}

\author{
By S. HERTZ AND A. ROBERTS \\ (From the Thyroid Clinic, Massachusetts General Hospital and the George Eastman Research \\ Laboratories, Massachusetts Institute of Technology, Boston)
}

(Received for publication July 28, 1941)

Recently, attention has been called to the importance of a special variety of Graves' disease which differs from the classic variety in that the ophthalmic manifestations become dissociated from the thyrotoxic (1). The characteristics of this special type, to which we shall refer as the ophthalmopathic type of Graves' disease, are: predominantly ocular symptomatology such as diplopia, chemosis, and edema; mild or absent thyrotoxic manifestations; normal or only slightly elevated basal metabolic rate; rapid decrease in metabolic rate to substandard levels upon administration of iodine; $a b-$ sence or relatively slight degree of enlargement of thyroid; and positive thyrotropic assays of blood and urine. The behavior of cases of classic Graves' disease toward radioactive iodine has been studied previously (2). We will now present parallel studies on the special ophthalmopathic type.

\section{PROCEDURE}

On the basis of previous experience (2), small doses of labelled iodine (less than $2 \mathrm{mgm}$.) were orally administered before any other treatment was given, especially before any other iodine. The thyroid iodine collection of the patient was followed by means of an externally placed Geiger-Müller counter and, in addition, urines were collected for $\mathbf{7 2}$ hours following the administration of the labelled iodine. (No appreciable iodine is excreted after this interval.)

The ophthalmopathic patients were compared directly with the classic type Graves' disease patients both as to thyroid collection and urinary excretion. Normal controls were also followed. The classic type patients were operated upon and the thyroid labelled iodine determined directly on the excised gland. The ophthalmopathic group was not operated upon, since operation is thought to be contraindicated in this group.

1 This research was supported principally by a grant from the John and Mary R. Markle Foundation, and also by a grant from the H. N. C. Gift for Medical and Surgical Research of Harvard University.

2 Presented at the American Society for Clinical Investigation meeting in Atlantic City, New Jersey, May 5, 1941.

\section{RESULTS}

The results of the external gamma ray measurements on the thyroid are shown in Figure 1. In this figure are plotted composite thyroid collection curves for each type of patient, as well as for normal patients. The results are given for 6 classic and 5 ophthalmopathic type patients and for 2 normal persons. The absolute value of the thy-

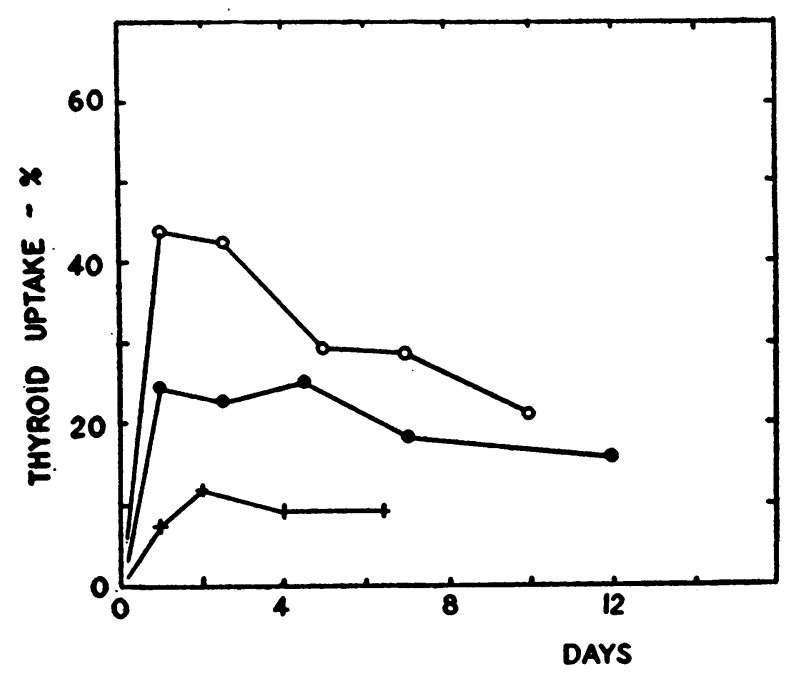

Fig. 1. Thyroid Uptake as a Function of Time After Administration of the Labelled Dose

The open circles are composite points for the classic type, the full circles for the ophthalmopathic type and the crosses for normal persons.

roid collection of labelled iodine in the ophthalmopathic group is not accurate and may be in error by as much as 50 per cent in any one case, although the composite has a smaller probable error. This error is due to individual variation in thyroid size and anatomy. The relative differentiation between the two types is borne out by the iodine excretion in the urine as shown in Figure 2.

The initial basal metabolic rates and the final levels after complete iodinization (after the meas- 


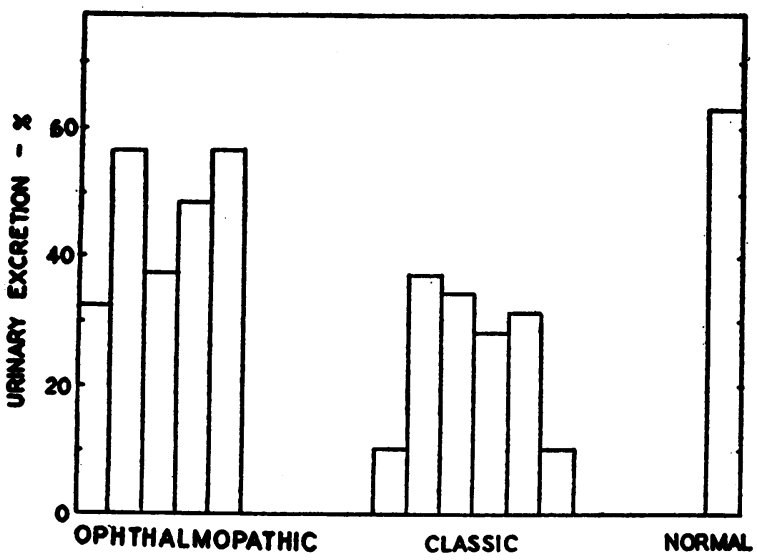

Fig. 2. Percentage of the Small Labelled Dose of Iodine Excreted Within 72 Hours by the Patients With Classic and Ophthalmopathic Types of Graves' Disease and One Normal Person

urements on the labelled dose were completed) are given in Table I.

TABLE I

\begin{tabular}{c|l|c|c|c}
\hline \hline Case & Type & $\begin{array}{c}\text { Initial basal } \\
\text { metabolic } \\
\text { rate }\end{array}$ & $\begin{array}{c}\text { Final basal } \\
\text { metabolic } \\
\text { rate }\end{array}$ & $\begin{array}{c}\text { Iodine } \\
\text { excretion } \\
\text { (per cent) }\end{array}$ \\
\hline 21 & Ophthalmopathic & -1 & -2 & 32 \\
23 & Ophthalmopathic & +46 & -8 & 56 \\
20 & Ophthalmopathic & +23 & -14 & 37 \\
19 & Ophthalmopathic & +15 & -9 & 48 \\
29 & Ophthalmopathic & +2 & -9 & 56 \\
22 & Classic & +42 & +26 & 10 \\
24 & Classic & +33 & 0 & 37 \\
27 & Classic & +55 & +31 & 34 \\
26 & Classic & +40 & +22 & 28 \\
18 & Classic & +29 & +5 & 31 \\
\hline
\end{tabular}

\section{DISCUSSION}

The difference in behavior between the two types of patients with Graves' disease is seen to be as follows: The ophthalmopathic group takes up less of the test dose of iodine in the thyroid and excretes more in the urine than the classic group, its behavior being in fact intermediate between the classic group and the normal. From this alone it might appear that the so-called ophthalmopathic group is merely a group of less severe classic cases.
That this is not the case is indicated by a study of the metabolic rates and the degree of response to complete iodinization. One of the distinguishing characteristics of the ophthalmopathic group is its exceptionally large response to iodinization, frequently to minus levels. A correlation study of the basal metabolic rate after iodinization shows that the rank correlation coefficient between the final basal metabolic level and the urinary excretion is -0.66 for all cases except the normal cases. This indicates that high urinary excretion of the test dose is well correlated with the level of basal metabolic response. The probability that this correlation is due to statistical fluctuation is $\mathbf{0 . 0 2}$.

Since the urinary excretion of a test dose is thus a good index of the type to which the patient belongs, this offers an additional convenient differential diagnostic aid. The use of labelled iodine for this purpose is not essential, provided that chemical methods for assaying the urinary iodine are available. Labelled iodine is merely a convenience for this purpose because of the great sensitivity and ease of the method.

\section{SUMMARY}

The ophthalmopathic type of Graves' disease patient excretes more iodine from a $2 \mathrm{mgm}$. (or less) test dose and takes up less in the thyroid than the classic Graves' disease patient. The urinary iodine excretion can be used as a diagnostic aid in distinguishing the two types of patients.

We are grateful for the generous interest and encouragement of Professor Robley D. Evans and Dr. J. H. Means.

\section{BIBLIOGRAPHY}

1. Hertz, S., Means, J. H., and Williams, R. H., Graves' disease with dissociation of thyrotoxicons and ophthalmopathy. Western J. Surg., 1941, 49, - .

2. Hertz, S., Roberts, A., and Salter, W. T., Radioactive iodine as an indicator in thyroid physiology. IV. The metabolism of iodine in Graves' disease. J. Clin. Invest., 1942, 21, 25. 